\title{
El renacimiento de un vitral y sus problemas legales
}

\author{
Irene Velaochaga Rey \\ Marisol Ginocchio Lainez - Lozada
}

En 1921, al conmemorarse el centenario de la independencia del Perú, la colonia italiana residente en nuestro país donó el Museo de Arte Italiano (MAI). El arquitecto italiano Gaetano Moretti se encargó del proyecto del edificio y Mario Vannini Parenti seleccionó las obras y los detalles ornamentales en Italia. El 11 de noviembre de 1923 se entregó oficialmente el museo.

Tanto el diseño como el decorado del edificio representan el arte italiano del pasado: elementos de la arquitectura de Bramante, relieves y detalles decorativos inspirados en Donatello, Ghiberti, Miguel Angel y Botticelli. La fachada se completa con los escudos de las principales ciudades italianas y dos gigantescos mosaicos con los personajes más notables de la historia italiana.

En cuanto a la colección, Vannini Parenti incluyó a representantes contemporáneos de todas las regiones italianas. Aconsejado por Ugo Ojetti, adquirió casi doscientas obras de más de cien artistas para el museo entre esculturas, pinturas, grabados, dibujos y cerámicas, que se convirtió en una muestra única del arte en Italia de principios de siglo, pese a que la vanguardia no está presente. Entre las obras se halla el vitral La Primavera, que ocupa gran parte de uno de los muros de la sala 2. A pesar de su importancia, pues es parte integrante del edificio, no se conocía a su autor; además, en los artículos de prensa publicados con motivo de la inauguración del museo, en 1923, no se le menciona y el único documento fotográfico lo registró Mauro Nicoletti, con una cámara de aficionado, horas antes de que el vitral sufriera daños.

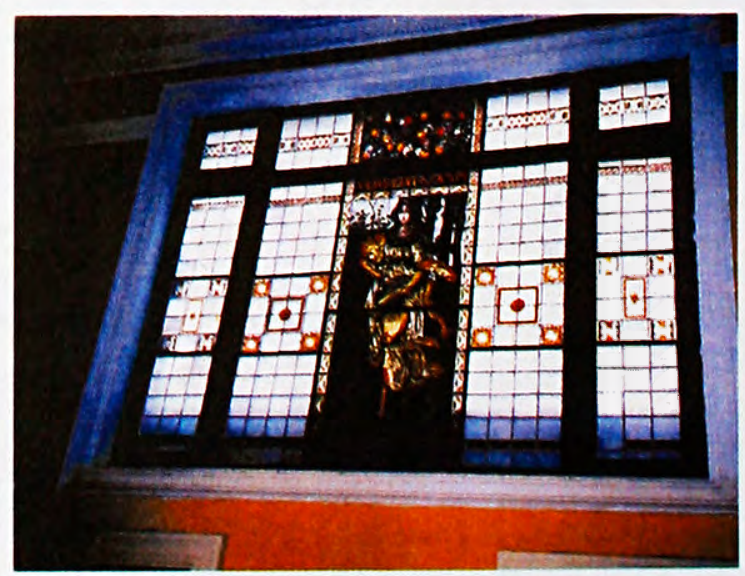


sólo se hallaron los siguientes documentos:

1. Una hoja suelta de un supuesto envío físico de bienes, en la que en mayo de 1986 el entonces director del Museo de Arte Italiano, César Coloma Porcari, describe el vitral.

2. El oficio $\mathrm{N}^{\circ}$ 100-86-A-MAI-INC, que el 6 de noviembre de 1986 enviaba César Coloma Porcari al jefe administrativo del Instituto Nacional de Cultura (INC). Era un presupuesto elaborado por Roberto Antonioli Teshiroqui para la "reparación y construcción de un ventanal del vitral La Primavera que se encuentra ubicado en la segunda sala del Museo de Arte Italiano".

3. El oficio № 116-86-A-MAI-INC (30 de diciembre de 1986), en el que el director del museo remitía al director general del INC, doctor Fernando Silva Santisteban, una relación de las obras realizadas en el Museo de Arte Italiano desde octubre de 1985. En él se indicaba que "también se restauró el gran vitral La Primavera, ubicado en la sala $2 "$.

Es claro que entre noviembre y diciembre de 1986 se restauró el vitral. Sin embargo, no se ha consignado qué piezas fueron repuestas o qué tipo de "reparación y reconstrucción" se efectuó. Tampoco se conoce si se realizaron restauraciones antes de 1985, aunque es muy posible ${ }^{1}$

4. En mayo de 1990, la entonces directora del Museo de Arte Italiano, Alicia Valladares Landa, publicó el artículo "Breve historia del Museo de Arte Italiano", en la revista Historia y Cultura $\left(N^{\circ} 19\right)$, editada por el Museo Nacional de Historia. Basada en una serie de artículos periodísticos publicados entre 1921 y 1923, ella dice: "Las grandes salas están iluminadas a través de amplias farolas; y los

\footnotetext{
${ }^{1}$ Hoy sabemos que hubo una restauración en 1942. posterior al terremoto de' 1940, hecha también por el laller de Roberto Antonioli Farfán (RAF). Uno de sus dibujantes firmó un vidrio de la pieza $K$ con la inscripción siguiente: "Zairely 6-1-192 RAF". "Zairely" era el seudónimo del dibujante Elifio Arias. Estos datos fueron facilitados por Agustín Antonioli, hijo de don Robero Antonioli y hoy a cargo del taller que ha cambiado de nombre por RAFSA. Esta inscripción no se encontró al efectuar el inventario de las piezas para la restauración, ya que fue una de las más dañadas. Una vez reconstruida por los restauradores, pudo leerse con claridad.
}

ábsides y la central por vitrales, este último polícromo y tiene por tema una alegoría de la primavera, basada en la obra La Primavera de Botticelli, de la cual se ha tomado el personaje principal La Primavera, lleva la siguiente inscripción Zairely 1922 RAF" 2.

Esta inscripción no se encontró al efectuar el inventario de las piezas luego del desmontaje. La pieza $\mathrm{K}$ era una de las más dañadas. Al restaurar el vitral y reconstruir el vidrio $\mathrm{K} 50$ pudo leerse claramente la inscripción: Zairely 6-1-1942 RAF3.

Toda información es valiosa y por ello resulta necesario conservar un archivo documental y fotográfico fechado que facilite la recuperación de un monumento, por partes o completo. Toda restauración o recuperación es más difícil si no se conoce la historia de aquello que se va a restaurar.

\section{Descripción del vitral}

El vitral está en la sala 2 (sala central) del museo, en el muro frente a la entrada. Se halla sobre las puertas que conducen a las oficinas y servicios.

Es un vitral engastado en plomo, con vidrios pintados y quemados a fuego. Consta de 19 piezas de diferentes tamaños, ordenadas en cinco franjas o paneles. Los dos extremos son ventanas: dos pequeñas en la zona superior (pieza A y pieza P) y dos largas formadas por las piezas $B, C$ y D, a la izquierda, y por las piezas $Q$, $R$ y $S$, a la derecha. Todas ellas, excepto las del centro, están formadas por vidrios rectangulares pavonados y algunos muestran motivos decorativos pintados.

\footnotetext{
2 Valladares, Alicia. Historia y Cultura $N^{\circ} 19$, revista del Museo Nacional de Historia. Lima, Peri, mayo 1990, pp. 90-91.

${ }^{3}$ Ver nota 1 .
} 


\author{
Esquema del vitral, con las letras \\ asignadas a cada panel durante el \\ desmontaje y embalaje.
}

La pieza I, arriba, al centro, tiene vidrios rectangulares pintados con follaje, frutas $y$ pájaros que forman una sola composición, excepto los vidrios más pequeños de los extremos de la derecha e izquierda, con motivos decorativos.

Las dos piezas grandes del centro ( $\mathrm{J}$ y K), además de los vidrios rectangulares con motivos decorativos a derecha e izquierda y los extremos superior e inferior con las frases Ver redit novum (en el extremo superior de la pieza J) y Omnia florent (en el extremo inferior de la pieza K) contienen vidrios de formas irregulares pintados con una interpretación del personaje de La Primavera, obra de Botticelli, que forma una única composición.

En la pieza $D$, en el extremo inferior derecho, aparece la siguiente inscripción: un monograma con las letras DAVM, y debajo, De Mattes. Firenze.

\section{Sucesos del 7 de febrero de $1992 y$ decisión de restaurar el vitral}

El 7 de febrero de 1992, debido a un atentado terrorista contra un edificio cercano, el museo sufrió graves daños. La onda expansiva afectó el vitral y dejó esparcidos miles de fragmentos. Cuatro paneles cayeron al suelo, entre ellos los dos centrales, con la figura de La Primavera; el resto tenía vidrios rotos o desprendidos y el plomo deformado. Sólo algunas piezas quedaron completas. Después de casi setenta años de existencia el museo perdió parte importante de una de sus obras artísticas.

La Dirección de Conservación de Bienes Muebles del Instituto Nacional de Cultura envió un equipo para que además de evaluar los daños recoja y asegure los vidrios y fragmentos de las piezas rotas; se desmontaron, además, dos piezas en peligro de caer. Después de examinar el vitral, el INC no envió al museo ningún informe.

Tras el atentado, el embajador de Italia, Bernardino Osio, y el presidente de la Asociación Amigos del Museo de Arte Italiano, ingeniero Gian Flavio Gerbolini, ofrecieron su ayuda para restañar los daños.

El embajador y Marco Curatola enviaron al día siguiente al restaurador italiano Roberto Nardi, quien dictaba un curso en el Museo de la Nación. Ellos coordinaron con el especialista para que estudiara la posibilidad de restaurar el vitral en el Centro de Conservación Arqueológica de Roma. Nardi envió en setiembre un informe completo del tratamiento que daría a la obra.

El director de Conservación de Bienes Muebles, Christiam Fiorentino, autorizó el envío del vitral completo, pese a que algunas piezas no habian sufrido mayores daños. La compañía aérea Alitalia lo transportó y la Embajada de Italia y la asociación asumieron los gastos de embalaje, trámites de aduana y restauración.

El primer problema fue el embalaje de las piezas, ya que la Dirección de Conservación de Bienes Muebles carecía de trabajadores suficientes. Por ello, el Museo de Arte Italiano dispuso que el personal a cargo de la arquitecta Marisol Ginocchio asumiera esa labor.

\section{Desmontaje y embalaje}

A fin de enviar el vitral a Italia, el 2 de octubre empezó el desmontaje de las piezas todavía sujetas a la ventana; muchas de ellas tenían vidrios rotos o desprendidos y el plomo deformado. Antes del desmontaje se aseguraron con cinta adhesiva los paneles y a cada uno se le asignó una letra con una etiqueta, para no equivocar su posición al reinstalarlos. 


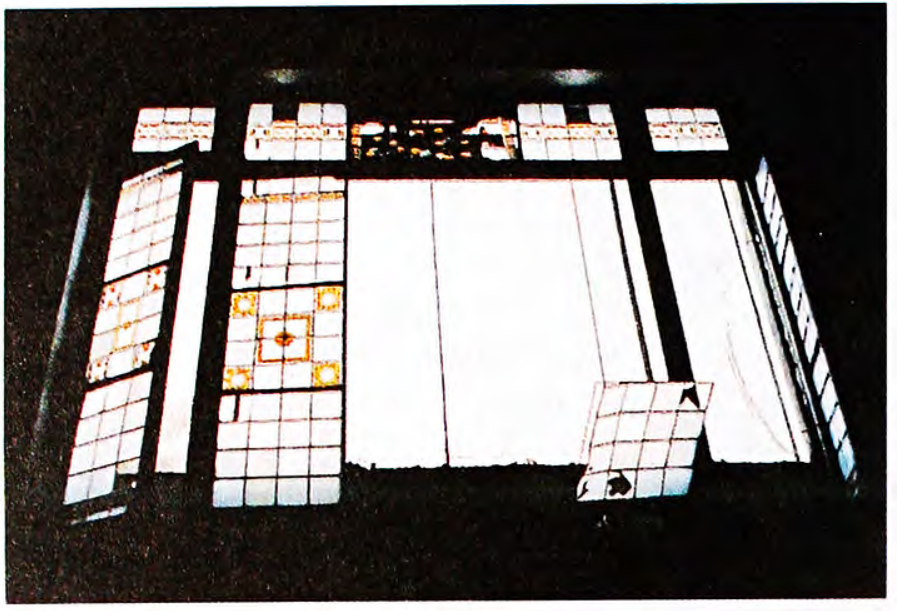

Estado en que quedó el vitral.

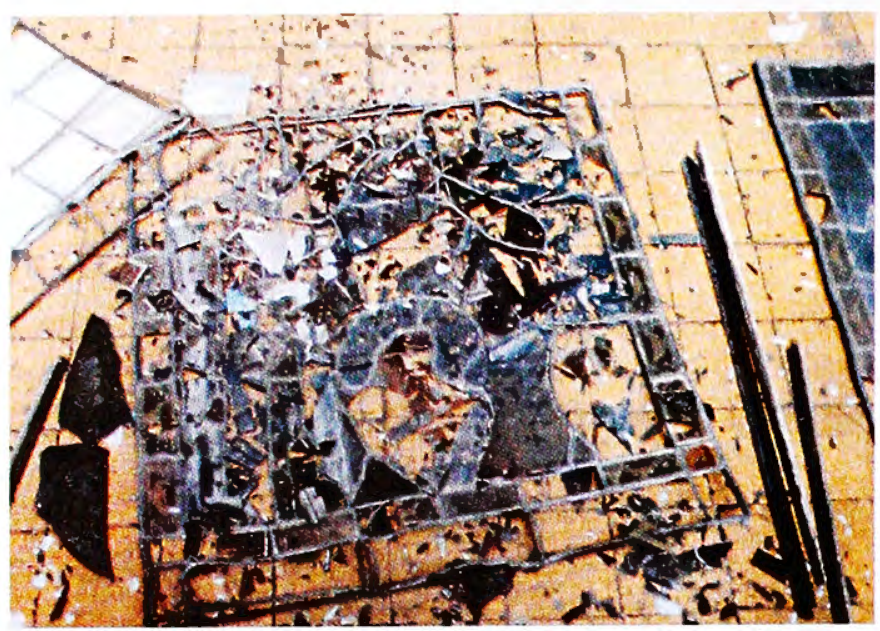

La pieza $\mathrm{J}$ en el suelo.

Los paneles desmontados se trasladaban a una sala acondicionada provisionalmente como taller. Las piezas se manipularon con mucho cuidado, ya que no se conocía qué daños habían sufrido los vidrios y plomos.

Por la estructura del vitral, los paneles no habian sido montados de la misma manera ni tenían igual grado o tipo de daño. Cada uno necesitó diferentes soluciones. Por ejemplo, las ventanas de los extremos se retiraron completas y las piezas se desmontaron en el taller.

Después de retirar la cinta adhesiva, se limpió toda la estructura con brocha y bencina seca. Luego se dibujaron las piezas pintadas y se fotografió cada panel por ambos lados. Al inventariar los vidrios y fragmentos se les asignó una etiqueta numerada; además, se evaluó la condición de cada pieza.
Con el fin de asegurar el traslado $y$ superar las dificultades que presentaban los paneles y vidrios se ensayaron diversas fórmulas de embalaje. Al final se decidió utilizar dunlopillo y teknopor, materiales que se adaptan a los cambios de temperatura y protegen las piezas.

Sistema de embalaje:

1. Se aseguró con masking tape la estructura de fierro a la pieza de vidrio y plomo en las zonas sueltas.

2. Los vidrios o fragmentos que aún estaban en su lugar se aseguraron con cinta engomada.

Debido a las condiciones de los vidrios se usaron varios procedimientos:

a. Los vidrios que estaban enteros se aseguraron con cinta en forma de equis;

b. Los vidrios fragmentados pero completos se unieron unos a otros y también al plomo;

c. Los vidrios fragmentados a los que le faltaban partes fueron asegurados entre ellos, y para sujetarlos al plomo se colocó por debajo una pieza de cartón doble, con el objeto de llenar el vacío.

d. Para cubrir los vacíos de los vidrios inexistentes se cortó el teknopor en piezas a la medida, de tres cuartos de pulgada de espesor, a fin de que quedaran al mismo nivel que la estructura de fierro.

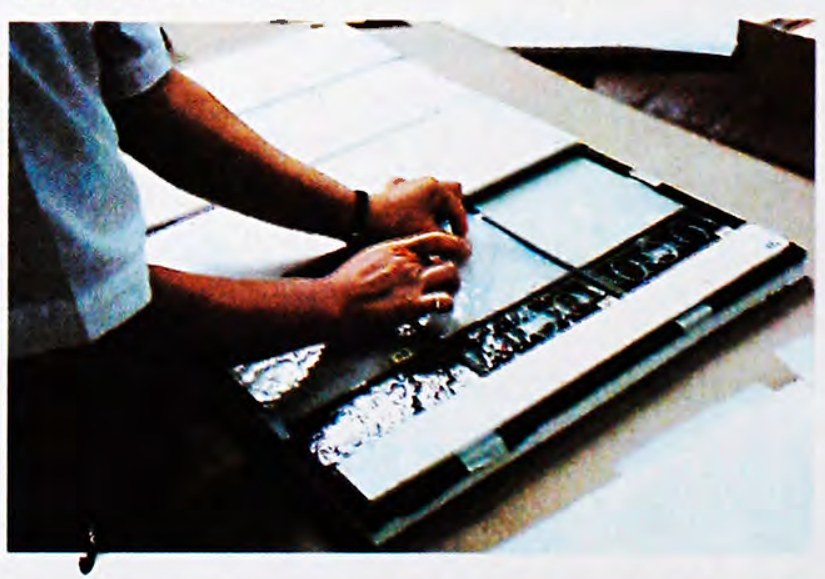

Los vidrios se aseguran con cinta engomada. Se rellenan los espacios con dunlopillo y teknopor. 
3. Sobre cada vidrio entero, fragmentado o fragmentado con faltantes se colocaron piezas de dunlopillo muy delgado (tres milímetros de espesor), a la medida del vidrio visible, con el objeto de darle la altura del plomo y no permitir que se formara una bolsa de aire entre el vidrio y el material de embalaje siguiente.

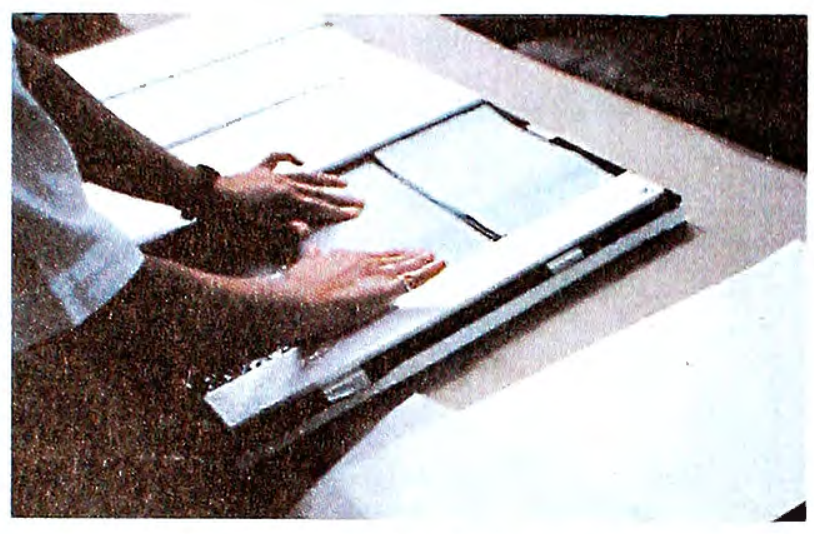

Se colocan piezas de dunlopillo sobre cada vidrio, para darle la altura del piomo.

4. En todas las zonas, excepto en las partes que tenían un vacío y ya se había colocado teknopor de tres cuartos de pulgada, se pusieron planchas de teknopor de media pulgada; así se les dio el nivel de la estructura de fierro.

5. Se numeraron con etiquetas las planchas de teknopor.

6. Esta pieza se colocó sobre una plancha de teknopor a su medida, cubierta con una lámina de tres milímetros de dunlopillo. Sobre la pieza se extendió una nueva lámina de dunlopillo y se cubrió con otra plancha de teknopor a su medida, igual a la de la base.

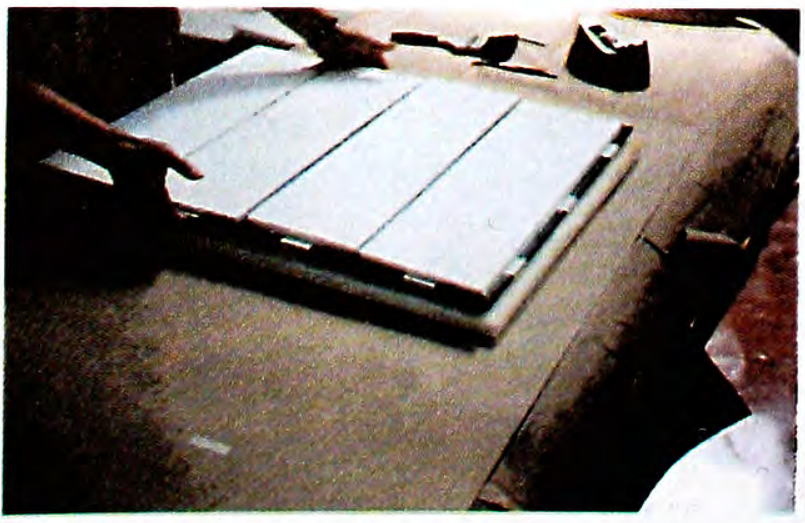

Se coloca la pieza armada sobre la base de teknopor cubierta por dunlopillo.
7. Encima de la cubierta se puso una etiqueta con el nombre y un dibujo simple de la pieza, así como un esquema en que se señalaba la posición que ésta ocupaba en el vitral completo.

8. Todo se aseguró, finalmente, con masking tape, sin ejercer presión, pero asegurando el paquete.

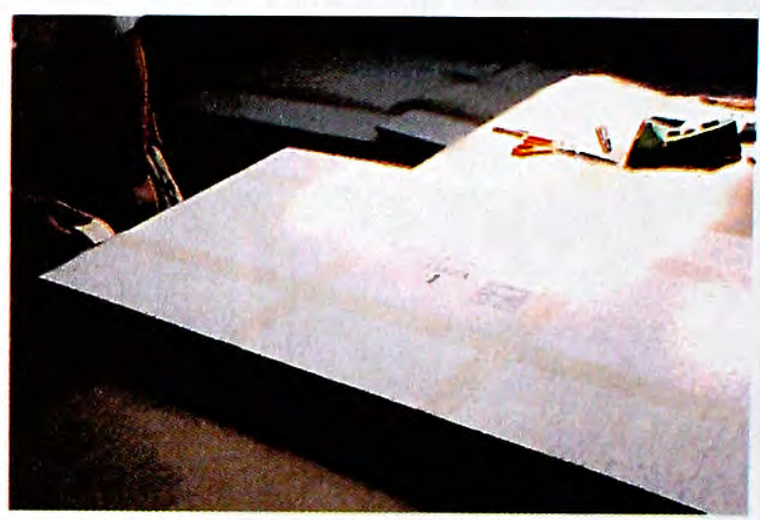

Se encinta con masking tape el paquete completo de la pieza para asegurarlo bien.

Fue difícil embalar las dos piezas centrales, las más dañadas, compuestas de vidrios irregulares y de tamaños distintos. Al dunlopillo y el teknopor se le dio la forma de cada uno de los vidrios, con el fin de protegerlos correctamente. El resto del procedimiento fue el mismo.

Los fragmentos sueltos y de ubicación desconocida se limpiaron, se clasificaron más o menos por color y tipo de vidrio y se embalaron sujetándolos a bandejas de teknopor. Todas las bandejas que contenian los fragmentos fueron cubiertas con dunlopillo de tres milímetros y se hicieron paquetes de tres bandejas cada uno; a la última se le colocó una nueva plancha de teknopor y todo se envolvió con masking tape.

Por considerar que no eran rescatables, no se enviaron los fragmentos microscópicos, pero se guardaron en el museo, en una caja de 20 por 20 centímetros 4 .

Al terminar el primer embalaje de todas las piezas acondicionadas individualmente, éstas

\footnotetext{
${ }^{4}$ Unos meses más tarde descubririamos que es fundamental conservar hasta el más mínimo fragmento. Todo es importante.
} 
se colocaron en una estructura sólida y segura para el transporte aéreo: dos armarios con cajones hechos a la medida.

Se emplearon doce para acomodar los paneles y fragmentos. Una semana después el embalaje final estaba completo. El 31 de octubre de 1992, ocho meses después del atentado, una nave de Alitalia trasladó las cajas al Centro de Conservación Arqueológica.

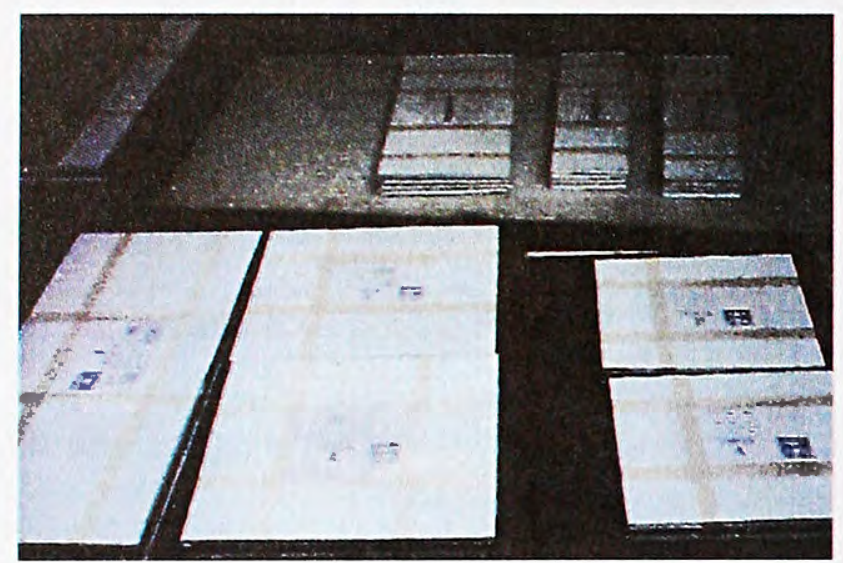

Las piezas preparadas para el embalaje final.

La primera etapa para salvar el vitral se había cumplido. La más difícil quedaba ahora en manos de los restauradores en Italia.

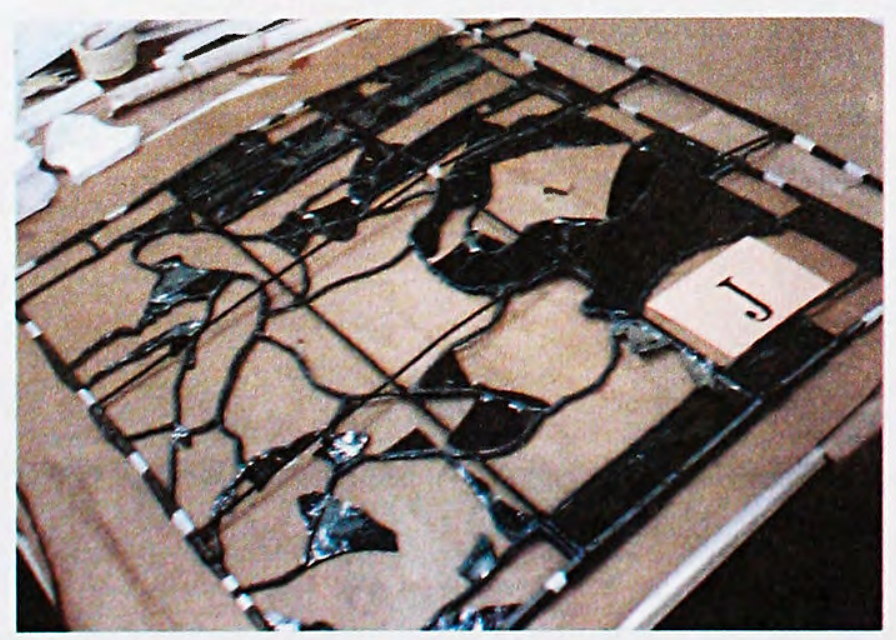

La pieza $\mathrm{J}$ antes de ser embalada.

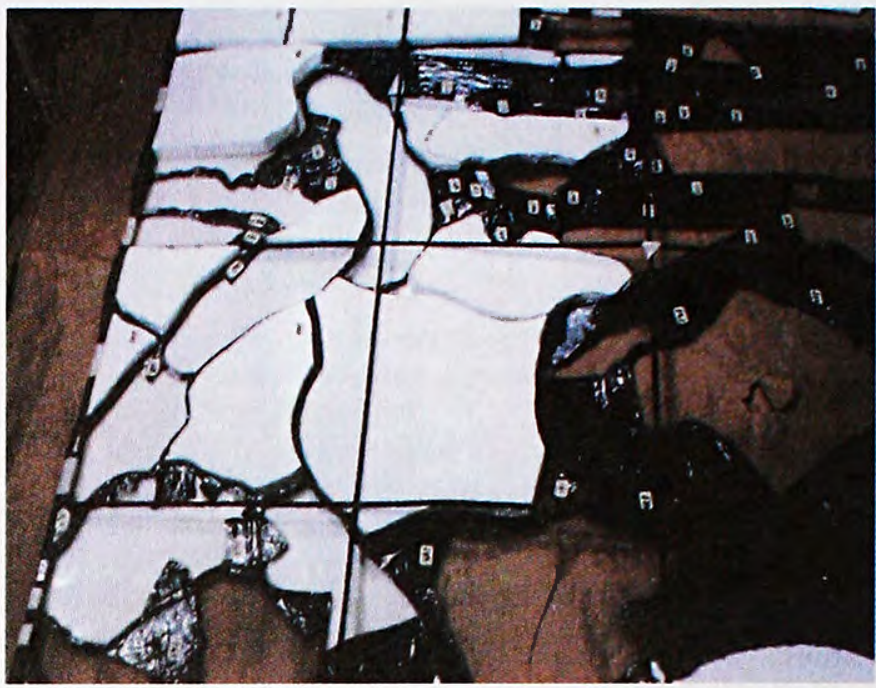

El embalaje de la pieza J.

El 26 de marzo de 1993, el profesor Nardi llamó desde Roma al Museo de Arte Italiano. Estaba sorprendido, pues si bien el museo fue minucioso para remitir fragmentos grandes y pequeños, en algunas zonas del vitral había muchos vacíos, sobre todo en los paneles centrales. El museo explicó al profesor Nardi que aún no había enviado a Roma una caja con fragmentos minúsculos, lo que se haría a la brevedad posible.

Después de limpiar y clasificar los pequeños fragmentos por color y tipo de vidrio, el personal del museo los acondicionó siguiendo un proceso similar al del embalaje de la primera remesa; luego, el $1^{\circ}$ de mayo, los envió, vía Alitalia.

\section{La restauración 5}

Los fragmentos de los 16 metros cuadrados de vitral llegaron a Roma en octubre de 1992 y se trasladan de inmediato al Laboratorio del Centro de Conservación Arqueológica, a cargo de Andrina y Roberto Nardi. Allí se inició a un largo y paciente trabajo para restaurar el vitral.

Era evidente la magnitud del problema, pues había que colocar nuevamente miles de

${ }^{5}$ Descripción hecha por los propios restauradores: Andreina y Roberto Nardi. 
fragmentos en su lugar, muchos de los cuales tenían color similar y dimensiones microscópicas.

Se empezó reagrupando los fragmentos según su espesor, color y tipo de fabricación. Esta operación preliminar facilitó la búsqueda y colocación de los numerosos elementos del enorme rompecabezas, cuyas piezas se fijaron temporalmente con pequeñas tiras de cinta adhesiva y cola instantánea.

Pese a que con el tiempo la vista se acostumbra a relacionar formas y colores, esta fase demandó más de la mitad de las energías de todo el proyecto. Sin embargo, las planchas tomaban forma lentamente.

Con compresas y medios mecánicos se aplicó un solvente para remover los depósitos de suciedad y las alteraciones debidas a la polución, así como las huellas del estuco original aplicado a pincel, el cual había perdido su transparencia inicial debido a la larga exposición a la luz.

Todas las fisuras y lagunas se sellaron con cera dental, aplicada en horma de líquido caliente para que se solidifique inmediatamente al contacto con el vidrio frío. Así, cada fisura tendría una superficie sellada y quedaría libre por dentro para recibir la resina del pegamento definitivo. Para esta última operación se utilizó una resina epóxica que garantizaba la calidad que requería la restauración del vidrio: fuerte capacidad adhesiva para unir fragmentos de poco espesor; absoluta estabilidad a la luz, a fin de evitar que se vuelva amarillo; resistencia al paso del tiempo y máxima fluidez para penetrar entre las fracturas.

El tratamiento de las partes faltantes necesitó de una serie de operaciones similares. La resina, vertida en moldes de cera, resultó transparente o ligeramente coloreada, según el tono cromático del vidrio original.

Al finalizar los trabajos de armado se notó que las líneas de fractura y las lagunas interferían visualmente con el diseño, lo que alteraba su legibilidad. Se decidió entonces completar pictóricamente las lagunas y retocar las líneas de fractura con acuarelas resistentes a la luz aplicadas a tratteggio. Este trabajo resultó extenso y requirió extrema exactitud. Hasta la más mínima fisura se completó y cada línea fue reconstruida.

Al término de esta compleja operación de retoque pictórico y acrílico, se aplicó con un aerógrafo una ligera película de resina. Esta operación se hizo sólo en las partes restauradas y sirvió para fijar el retoque de la acuarela, que de otra manera sería soluble al agua. Las piezas así preparadas se colocaron de nuevo en su lugar, dentro de perfiles de plomo que se sueldan entre sí para encerrar el tramado estructural de cada . panel.

El efecto de la intervención resultó sorprendente: todos los fragmentos estaban nuevamente en su lugar. Los restauradores habían superado el reto. Había desaparecido el velo de suciedad que opacaba todo. La obra del artista se mostraba en toda su calidad y el color se expresaba vivo en un triunfo de luz.

Extremado es tal vez el término más justo para definir la restauración, tanto por las condiciones de partida como por las soluciones técnicas adoptadas, pero extremada es también la satisfacción de quienes han visto renacer, lenta pero progresivamente, una obra de arte que se creía destruida.

\section{Los problemas de los trámites}

A los esfuerzos desplegados para recuperar el vitral se aunaron una serie de trámites legales en el INC y la Intendencia de Aduana Aérea, los cuales se complicaron después por una simple falla en el proceso.

En setiembre de 1992 se recibió el informe del restaurador. El Museo de Arte Italiano lo envió a la Dirección de Conservación de Bienes Muebles del Instituto Nacional de Cultura para que lo aprobara, ya que el vitral forma parte del edificio del museo, declarado Patrimonio 
Nacional. La Dirección de Conservación envió el 15 de setiembre, mediante oficio, su opinión acerca del tratamiento que el profesor Nardi propuso para la obra en el Centro de Conservación Arqueológica de Roma. En ese oficio se aprobó la intervención y se sugirió el envío del vitral completo.

A su vez, el encargado de negocios de la Embajada de Italia ante la ausencia del embajador envió el 2 de octubre una carta al jefe del Instituto Nacional de Cultura, en la que solicita autorizar la salida de las piezas del vitral, con el objeto de gestionar los trámites correspondientes. El Museo de Arte Italiano remitió el 7 de octubre un oficio, en el que pedía también al jefe del INC que autorizara y facilitara la salida de las piezas del vitral.

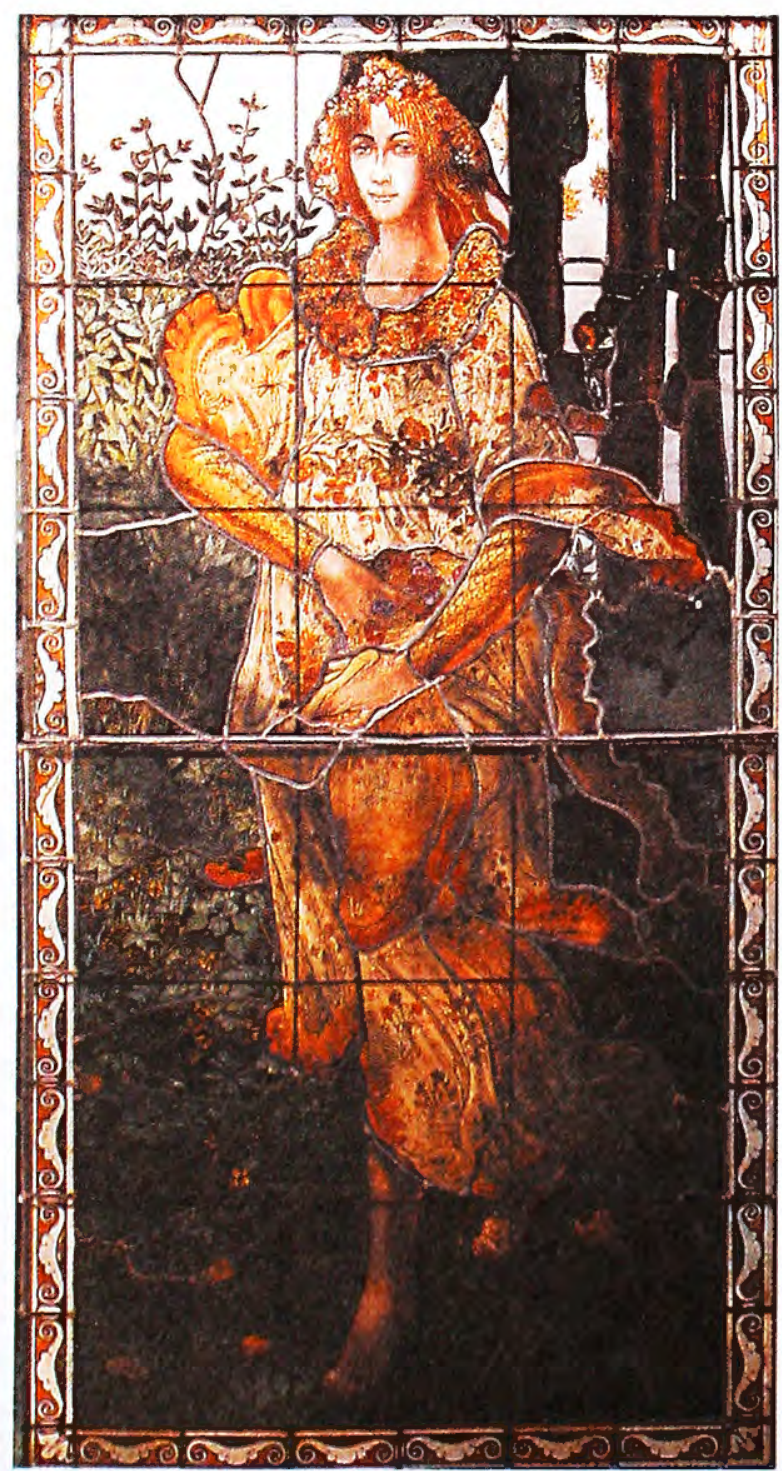

El 21 de octubre se expidió la Resolución Jefatural № 783 del INC, debido a que era necesario que el vitral llegara a Roma lo más pronto posible, como lo deseaba la Embajada de Italia en el Perú y lo solicitaba el Centro de Conservación Arqueológica de Roma, y teniendo en cuenta, además, que la emisión de una resolución suprema 6 tarda cerca de tres meses.

Con ese documento se autorizó la exportación temporal del vitral para su restauración, con las visaciones de la Dirección General de Museos, de la Dirección General de Inventario, Catalogación, Registro e Investigación del Patrimonio Cultural, y de la Oficina de Asesoría Jurídica del INC; de conformidad con lo dispuesto en la Ley General de Amparo al Patrimonio Cultural de la Nación, Ley № 24047 y disposiciones pertinentes de los Decretos Supremos № 01-84-ED, № 17-84-ED, № 14-91ED y la Resolución Jefatural № 1003-91-INC/J7.

El 31 de octubre, la empresa de transportes contratada por la Asociación Amigos del Museo de Arte Italiano se ocupó de todos los trámites aduaneros para que las cajas del vitral salgan del país. Los papeles incluían, además de la resolución jefatural, un pedido de exportación temporal del vitral y una carta de fianza moral, emitidos por el Museo de Arte Italiano y dirigidos a la Intendencia de Aduana Aérea (IAA).

Cumplidos los trámites legales, el museo no se preocupó del asunto hasta abril de 1993, cuando fue necesario solicitar a la IAA una prórroga de la licencia de exportación temporal, que vencía en abril.

Con la recomendación de la empresa de transportes, el museo elaboró el 31 de marzo una nueva carta de fianza moral, en los mismos términos que la del 31 de octubre del año anterior, y un pedido de prórroga de licencia de exportación temporal por seis meses.

El 5 de abril la empresa de transportes recogió ambas cartas dirigidas al intendente de Aduana Aérea, junto a una carta del Museo de

${ }^{6}$ Una Resolución Suprema hubiera evitado los problemas posieriores.

${ }^{7}$ La Resolución Jefatural sólo tiene una vigencia de seis meses renovables. 
Arte Italiano, enviada a la encargada de trámites aduaneros, quien aseguró que todo estaba en orden, pero que le era imposible enviar los cargos solicitados porque formaban parte del expediente que la empresa tenía que conservar.

Cumplidos nuevamente los trámites legales, el museo no se ocuparía del asunto hasta octubre y sólo si la restauración demoraba más de lo previsto.

Dos meses después, el 14 de junio, el profesor Nardi manifestaba en una carta que la restauración del vitral no podría concluirse hasta noviembre debido a que otros trabajos del Centro de Conservación Arqueológica de Roma habían generado ciertos problemas.

Considerando que la prórroga de la licencia de exportación temporal vencería en octubre, el 13 de setiembre se le consultó a la empresa de transportes cómo solicitar una nueva prórroga. La encargada de trámites aduaneros ya no era la misma y la nueva funcionaria manifestó, después de revisar el expediente, que le enviaran otra carta de fianza moral, así como un pedido de prórroga de la licencia de exportación temporal por seis meses más.

El 15 de setiembre, el Museo de Arte Italiano remitió a la empresa de transportes ambos documentos, dirigidos a la Intendencia de Aduana Aérea.

Sin embargo, el 8 de octubre la Intendencia de Aduana Aérea emite la Res. Div. $N^{\circ} 000262$, que señala que no acepta el pedido de prórroga por ser extemporáneo y que el vitral debía regresar al país en quince días. Este documento llegó al museo el 14 de octubre, junto con una notificación de la IAA.

Como el museo había cumplido con todos los trámites legales, sus autoridades no comprendían el porqué de la declaratoria de extemporaneidad y por eso preguntaron a la empresa de transportes qué había motivado esa resolución.
El 25 de octubre, la empresa de transportes, sin explicar la causa para que la intendencia declarara extemporáneo el pedido de prórroga, sugirió que el Museo de Arte Italiano solicite al INC una resolución jefatural para prorrogar la autorización de exportación temporal expedida en octubre de 1992. Agregaba que el museo debía enviar, junto con la resolución, una carta para pedir que se reconsidere la Res. Div. $N^{\circ} 000262$, emitida por la Intendencia de Aduana Aérea, y que esa misiva tenía que ser firmada por un abogado.

El 10 de noviembre, la Oficina de Asesoría Jurídica del Instituto Nacional de Cultura revisó los documentos remitidos por el museo en octubre y consideró que no era necesario el trámite sugerido por la encargada de trámites aduaneros, pues el museo no había cometido falta alguna ni era extemporáneo el pedido de prórroga solicitado en setiembre. Pidió entonces que el MAI enviara los cargos de las cartas de marzo $^{8}$, incluidos en el expediente que manejaba la Oficina de Asesoría Jurídica del Instituto Nacional de Cultura.

El 23 de noviembre, con el plazo casi vencido, la Oficina de Asesoría Jurídica informó que para contrarrestar la resolución de la Intendencia de Aduana Aérea se necesitaba el cargo del pedido de prórroga de la licencia de exportación temporal de marzo y no el de la carta de fianza moral.

Se solicitó el documento a la empresa de transportes y entonces se descubrió cuál era el problema de fondo: ésta no tenía en el expediente el cargo que demostrara que se había recibido el pedido de prórroga de la licencia de exportación temporal de marzo. Con eso se dedujo que el pedido nunca llegó a manos de la Intendencia de Aduana Aérea y, por lo tanto, se había cometido una falta desde abril9.

Al día siguiente, 24 de noviembre, se vencía el plazo para solicitar que se reconsidere la Res. Div. N 000262 de la Intendencia de

\footnotetext{
${ }^{9}$ Lógicamente, el nuevo pedido de prórroga de setiembre se convertía así en extemporineo, ya que la licencia de exportación temporal había vencido en abril.
} 
Aduana Aérea, y aún no se había realizado ningún trámite. La empresa de transportes, responsable de lo ocurrido, consultó con la Intendencia de Aduana Aérea para solucionar el problema legal.

La empresa de transportes comunicó el 25 de noviembre que la Intendencia de Aduana Aérea manifestaba que sólo había dos soluciones posibles:

1. Solicitar un plazo de quince días para traer el vitral inmediatamente, estuviera concluida o no la restauración.

\section{Solicitar la exportación definitiva del vitral.}

Por tal razón, el Museo de Arte Italiano decidió solicitar directamente al jefe del Instituto Nacional de Cultura la única solución posible para el bien del vitral: una resolución suprema. Esa disposición sufrió después innumerables demoras porque el Ministerio de Educación la devolvió varias veces al Instituto Nacional de Cultura al detectar errores de redacción.

\section{La llegada del vitral y el problema legal}

El 12 de mayo de 1994 el vitral llegó a Lima, pero la Embajada de Italia no pudo retirarlo de la aduana porque no tenía la documentación en regla y aún no se había emitido la resolución suprema solicitada al INC desde fines de noviembre del año anterior.

A partir de entonces el personal del museo buscó solucionar el problema, a fin de que el vitral restaurado permaneciera lo mínimo indispensable en los depósitos de la Aduana, ya que en ese lugar no tenía las mínimas condiciones para su conservación.

A través de consultas directas con la Embajada de Italia, la Cancillería, el superintendente adjunto de Aduana Aérea, se convino en enviar la copia autenticada de la resolución suprema en cuanto fuera recibida.
El martes 17 de mayo, en conferencia de prensa en el Museo de Arte Italiano, se presentó a todo el país, a través de los medios de comunicación, el vitral totalmente restaurado.

La Resolución Suprema N 107-94-ED, emitida el $1^{\circ}$ de agosto de 1994 , autorizó la prórroga del permiso de exportación temporal hasta que concluyeran los trabajos de restauración. Se publicó el 3 de agosto en el Diario Oficial El Peruano. La copia autenticada de esa resolución suprema la envió el Instituto Nacional de Cultura al Museo de Arte Italiano el 18 de octubre, y ese mismo día se remitió al Departamento de Regímenes Temporales de la Intendencia de Aduana Aérea.

\section{Las lecciones aprendidas}

A pesar del grave problema surgido, los días jueves 12 , viernes 13 y lunes 16 se hicieron trámites y entrevistas con muchas personas de buena voluntad para que se comprendiera que el fin era recuperar el patrimonio nacional, y que más allá de los errores de una empresa de transportes estaba el interés de instituciones y autoridades por devolver al Museo de Arte Italiano el vitral totalmente restaurado.

Muchas fueron las lecciones aprendidas, tanto en el tema de conservación y responsabilidad con una obra de arte como en lo referente a los trámites legales.

En el caso de la conservación y cuidado de una obra de arte, las lecciones aprendidas fueron:

Primero, es de suma importancia conservar todos los documentos escritos y fotográficos (siempre fechados) de una obra de arte, ya sea una pieza de la colección del museo o un detalle arquitectónico de un monumento.

Segundo, todo fragmento, por minúsculo que sea, puede resultar fundamental para la integridad de la obra. 
En tercer lugar, cuando no se conocen métodos de embalaje para una obra de características poco comunes, es necesario consultar con los especialistas en conservación. Si éstos desconocen el tema, es absolutamente necesario pedir opiniones y estudiar muy bien todas las posibilidades antes de empezar el trabajo. Debe tenerse mucho cuidado con el tipo de materiales y prever todas las eventualidades en el transporte. Es importante también emprender sin miedo el trabajo, cuidar siempre los detalles más pequeños y estar dispuestos a enmendar errores en el camino.

En la conservación de una obra de arte, más vale exagerar las previsiones que quedarse corto en ellas.

Pero las lecciones más importantes fueron las referidas a los trámites legales:

En primer lugar, hay que tener en cuenta que los trámites no son complicados, pero es necesario conocerlos y saber el tiempo que tarda cada caso.

En segundo término, es importante tomar conciencia de que nadie es infalible $y$, por lo tanto, es indispensable hacer un seguimiento cuidadoso y constante de todos los pasos, procurando conservar siempre las constancias que demuestren el cumplimiento de cada uno de ellos.

En tercer lugar, que los papeles son fríos y hay un desconocimiento muy grande de lo que significan los asuntos culturales y patrimoniales. Esto complica más cualquier problema, por pequeño que éste sea. Es necesario tratar directamente con las personas, gracias a cuya comprensión y buena voluntad puede solucionarse cualquier problema, por más difícil que parezca.

Es fundamental, sobre todo, tener en cuenta que no se debe fallar en los trámites legales. 